\title{
COMPOSIÇÃO DE AMINOÁCIDOS DE GERAÇÕES PRECOCES DE FEIJÃO OBTIDAS A PARTIR DE CRUZAMENTOS COM PARENTAL DE ALTO TEOR DE METIONINA ( $\left.{ }^{1}\right)$
}

\author{
NERINÉIA DALFOLLO RIBEIRO $\left({ }^{2 *}\right)$; PATRÍCIA MEDIANEIRA GRIGOLETTO LONDERO $\left({ }^{3}\right)$; \\ ALBERTO CARGNELUTTI FILHO $\left({ }^{2}\right)$; EVANDRO JOST $\left({ }^{3}\right)$
}

\begin{abstract}
RESUMO
O objetivo deste trabalho foi avaliar a composição de aminoácidos de gerações precoces de feijão, obtidas a partir de cruzamentos com parental de alto teor de metionina, e selecionar plantas $F_{2}$ para o desenvolvimento de populações segregantes com alto teor de metionina. A partir do cruzamento entre BRS Valente e IAPAR 44 foram obtidas as gerações $F_{1}, F_{1}$ recíproco, $F_{2}, F_{2}$ recíproco, retrocruzamento 1 e retrocruzamento 2. Os aminoácidos foram quantificados por cromatografia líquida de alta eficiência (CLAE) e os dados obtidos foram submetidos à análise de variância e de variáveis canônicas. Os aminoácidos ácido aspártico, ácido glutâmico, glicina, prolina, tirosina, cisteína, metionina e treonina - apresentaram variabilidade genética. Gerações precoces com alto teor de metionina foram obtidas sem que tenha havido limitação na disponibilidade dos demais aminoácidos essenciais. As duas primeiras variáveis canônicas explicaram 99,28\% da variação total dos genótipos e três grupos foram formados. Plantas da geração $F_{2}$ poderão ser selecionadas pelo programa de melhoramento para o desenvolvimento de populações segregantes de feijão com alto teor de metionina.
\end{abstract}

Palavras-chave: Phaseolus vulgaris L., qualidade protéica, variabilidade genética, variáveis canônicas.

\section{ABSTRACT \\ AMINO ACID COMPOSITION IN COMMON BEAN OF EARLY GENERATIONS DEVELOPED FROM CROSS WITH HIGH METHIONINE CONTENT PARENTAL}

The objective of this research was to determine the amino acid composition in common bean early generations developed from controlled crossings with high methionine content parental, and to select $\mathrm{F}_{2}$ plants with high methionine content. BRS Valente and IAPAR 44 were crossed and the $\mathrm{F}_{1}, \mathrm{~F}_{1}$ reciprocal, $\mathrm{F}_{2}, \mathrm{~F}_{2}$ reciprocal, backcross 1 e backcross 2 generations were obtained. The amino acid contents were determinated by liquid chromatography of high performance (CLAE) and the data were submitted to analysis of variance and cannonical variables. Aspartic acid, glutamatic acid, glycine, proline, tyrosine, cysteine, methionine and threonine contents showed variability among genotypes. Early generations were obtained with high methionine content and essential amino acids contents were appropriate for consume. The first two cannonical variables explained $99.28 \%$ of the total variation of genotypes and three groups were formed. Plants of the $\mathrm{F}_{2}$ generation are able to be selected by breeding program for the development of segregation populations of common bean with high methionine content.

Key words: Phaseolus vulgaris L., protein quality, genetic variability, cannonical variables.

${ }^{1}$ ) Recebido para a publicação em 18 de março de 2009 e aceito em $1 .^{\text {a }}$ de setembro de 2009.

$\left({ }^{2}\right)$ Departamento de Fitotecnia, Centro de Ciências Rurais, Universidade Federal de Santa Maria (UFSM), 97105-900 Santa Maria (RS). E-mail: nerineia@hotmail.com $\left(^{*}\right)$ Autora correspondente.

$\left({ }^{3}\right)$ Aluno do Programa de Pós-graduação em Agronomia da UFSM. 
O feijão (Phaseolus vulgaris L.) é deficiente em metionina, mas possui em sua constituição todos os demais aminoácidos essenciais (AвD EL-SAMEI e LÁsZTity, 1984; Antunes et al., 1995; FonSECA Marques e Bora, 2000; Guzmán-MaldonAdo et al., 2000; Pires et al., 2006). Por isso, sua proteína tem sido considerada de baixo valor nutritivo.

No entanto, Ribeiro et al.(2007) observaram que em várias cultivares de feijão, disponíveis para o cultivo no Brasil, havia teores de aminoácidos essenciais e não-essenciais adequados para suprir as necessidades nutricionais diárias de um indivíduo adulto, de acordo com o padrão considerado pela Organização das Nações Unidas para Agricultura e Alimentação (FAO, 1998). Além disso, em vários artigos relata-se que na composição de aminoácidos em feijão há diferenças genéticas (ABD EL-SAMEI e LÁSZTITY, 1984; Antunes et al., 1995; Fonseca Marques e Bora, 2000; GuZMÁn-Maldonado et al., 2000). Portanto, é possível identificar cultivares de feijão com alta qualidade protéica.

A metionina é o aminoácido essencial presente em menor concentração no feijão (ANTUNES et al., 1995; Fonseca MARQues e Bora, 2000; Ribeiro et al., 2007) e seu aumento, pelo melhoramento genético, é desejável para que se obtenha uma proteína de melhor qualidade. Como o feijão possui baixo teor de gordura e não contém colesterol (Hosfield, 1991; Morrow, 1991), dietas menos calóricas e mais nutritivas poderiam ser formuladas a partir da cultivar geneticamente modificada.

Considerando que herdabilidade, em sentido restrito, moderada $(0,43$ a 0,56$)$ e ação gênica aditiva foram verificadas para metionina em feijão (Kelly e BLISS, 1975), espera-se eficiência na seleção em populações com variabilidade genética e o consequente desenvolvimento de germoplasma com maior teor de aminoácidos sulfurados. Até o presente, não se tem conhecimento se o incremento no teor de metionina em grãos de feijão pode limitar a disponibilidade dos demais aminoácidos.

Desse modo, o objetivo desse trabalho foi avaliar a composição de aminoácidos de gerações precoces de feijão, obtidas a partir de cruzamentos com parental de alto teor de metionina, e selecionar plantas $F_{2}$ para o desenvolvimento de populações segregantes com alto teor de metionina, sem comprometer a disponibilidade dos outros aminoácidos.

A partir dos resultados observados por RiBEIRO et al. (2007), selecionaram-se dois parentais contrastantes para o teor de metionina (1. BRS Valente: 0,79 gramas por $16 \mathrm{~g} \mathrm{~N}$ e 2. IAPAR 44:
0,97 gramas por $16 \mathrm{~g} \mathrm{~N}$ ). Os cruzamentos dirigidos entre os dois parentais foram realizados com emasculação do botão floral, por meio de entrelaçamento, em casa de vegetação em 2006. No período de outono/inverno de 2006, foram obtidas as sementes $F_{1}\left(1 \% \times 20^{\prime \prime}\right)$ e $F_{1}$ recíproco $\left(2+\times 10^{\prime \prime}\right)$. Estas foram semeadas entre a primavera e o verão de 2006 para a obtenção das sementes $F_{2}$ (autofecundação das plantas $F_{1}$ ), $F_{2}$ recíproco (autofecundação das plantas $\mathrm{F}_{1}$ recíproco), retrocruzamento $1\left(\mathrm{RCP}_{1}: \mathrm{F}_{1} \times 1\right)$ e retrocruzamento $2\left(\mathrm{RCP}_{2}: \mathrm{F}_{1} \times 2\right)$. Sementes $\mathrm{F}_{1}$ e $\mathrm{F}_{1}$ recíproco foram novamente obtidas, na segunda época, para possibilitar a avaliação de sementes desenvolvidas sob as mesmas condições ambientes e com a mesma idade.

As plantas de feijão foram cultivadas em vasos plásticos, com capacidade para 5 litros da mistura solo + substrato comercial Plantimax ${ }^{\circledR}+$ casca de arroz carbonizada, na proporção volumétrica de 2:1:1. O solo utilizado foi o Alissolo Hipocrômico argilúvico típico e a correção da fertilidade realizada para os minerais considerados limitantes no solo.

A fim de garantir o desenvolvimento normal das plantas de feijão e a integridade dos botões florais foram realizadas irrigações diárias. O controle de insetos e de doenças foi efetuado sempre que necessário. As vagens de feijão foram colhidas individualmente na maturação e os grãos, secos em estufa a 65 a $70{ }^{\circ} \mathrm{C}$, até umidade média de $13 \%$, e moídos em micromoinho até a obtenção de partículas inferiores a $1 \mathrm{~mm}$. As amostras foram armazenadas em embalagens plásticas e conservadas sob refrigeração $\left(0^{\circ} \mathrm{C}\right)$ até a realização das análises.

A determinação dos teores de aminoácidos foi realizada por cromatografia líquida de alta eficiência (CLAE). As amostras passaram por hidrólise prévia com ácido clorídrico $6 \mathrm{~N}$ bidestilado, a $110{ }^{\circ} \mathrm{C}$ durante 24 horas, seguida de derivação pré-coluna dos aminoácidos livres com fenilisotiocianato (PITC). A separação dos derivados feniltiocarbamil-aminoácidos (PTC-aa) foi efetuada em coluna de fase reversa C18 (Pico-Tag - 3,9 × $300 \mathrm{~mm}$ ) e para a detecção empregouse detector UV a $254 \mathrm{~nm}$ (ELKIM e WASYNEZUK, 1987; Hagen et al., 1989). A quantificação dos aminoácidos foi baseada na altura de cada pico do derivado, tendose usado como referência a altura do pico do padrão interno de aminoácidos com concentração conhecida. Os teores de aminoácidos foram transformados em gramas por $16 \mathrm{~g}$ de nitrogênio, em base seca. Para isso, o teor de nitrogênio da amostra foi determinado pelo método de micro-Kjeldahl (AOAC, 1995). Os teores de aminoácidos e de proteína bruta foram quantificados em duplicata. 
As análises estatísticas foram efetuadas segundo o modelo inteiramente casualizado, com duas repetições para os genitores $\left(\mathrm{P}_{1}\right.$ e $\left.\mathrm{P}_{2}\right)$ e para as gerações $F_{1}, F_{1}$ recíproco, $R C P_{1}$ e $R C P_{2}$ e quatro repetições para as gerações $F_{2}$ e $F_{2}$ recíproco. Os dados obtidos foram submetidos à análise de variância, utilizando-se o teste $\mathrm{F}$ a $5 \%$ de probabilidade de erro. As médias foram comparadas entre si pelo teste $t$ a $5 \%$ de significância. A partir das médias e da matriz de variância e de covariância residual dos aminoácidos em que se obtiveram diferenças significativas entre os genótipos, avaliou-se a dissimilaridade genética por meio de variáveis canônicas, conforme descrito em Cruz e Regazzi (2001).

Diferenças significativas para genótipos foram constatadas para os aminoácidos - ácido aspártico, ácido glutâmico, glicina, prolina, tirosina, cisteína, metionina e treonina, e para o teor de proteína bruta (Tabela 1). A variabilidade genética revelada pelos resultados indica a possibilidade de seleção de germoplasma de feijão pela composição de aminoácidos.

Tabela 1. Composição de aminoácidos não essenciais e essenciais (em gramas por $16 \mathrm{~g}$ de $\mathrm{N}$, em base seca) e de proteína bruta (em gramas por $100 \mathrm{~g}$ de matéria seca) de grãos de feijão dos genitores e gerações obtidas a partir do cruzamento entre BRS Valente e IAPAR 44

\begin{tabular}{|c|c|c|c|c|c|c|c|c|c|c|}
\hline \multirow{3}{*}{$\begin{array}{l}\text { Genitor e } \\
\text { Geração } \\
\text { BRS Valente }\end{array}$} & \multicolumn{10}{|c|}{ Aminoácidos não essenciais } \\
\hline & \multirow{2}{*}{$\begin{array}{c}\begin{array}{c}\text { Ácido } \\
\text { Aspártico }\end{array} \\
16,04 \mathrm{a}^{*}\end{array}$} & \multirow{2}{*}{$\begin{array}{c}\text { Ácido } \\
\text { Glutâmico } \\
18,25 \mathrm{a}^{*}\end{array}$} & \multirow{2}{*}{$\begin{array}{l}\text { Serina } \\
6,07^{\mathrm{ns}}\end{array}$} & \multirow{2}{*}{$\begin{array}{l}\text { Glicina } \\
2,70 \mathrm{~b}^{*}\end{array}$} & \multirow{2}{*}{$\begin{array}{l}\text { Alanina } \\
3,52 \mathrm{~ns}\end{array}$} & \multirow{2}{*}{$\begin{array}{l}\text { Prolina } \\
1,80 \mathrm{c}^{*}\end{array}$} & \multicolumn{2}{|c|}{ Tirosina } & Arginina & Cisteína \\
\hline & & & & & & & 2,44 & $\mathrm{~d}^{*}$ & 7,34 ns & $1,20 \mathrm{a}^{*}$ \\
\hline IAPAR 44 & $13,24 \mathrm{ab}$ & $15,10 \mathrm{~b}$ & 5,84 & $3,21 \mathrm{ab}$ & 3,66 & $2,14 \mathrm{c}$ & 2,87 & $\mathrm{~cd}$ & 6,50 & $1,28 \mathrm{a}$ \\
\hline $\mathrm{F}_{1}$ & $9,25 \mathrm{c}$ & $15,44 \mathrm{~b}$ & 5,49 & 3,54 a & 3,85 & $3,97 \mathrm{ab}$ & 3,66 & $a b$ & 6,73 & $0,72 \mathrm{c}$ \\
\hline $\mathrm{F}_{1}$ recíproco & $10,14 \mathrm{c}$ & $13,75 \mathrm{~b}$ & 4,96 & 3,34 a & 3,39 & 4,33 a & 3,22 & $\mathrm{bc}$ & 5,62 & $0,69 \mathrm{c}$ \\
\hline $\mathrm{F}_{2}$ & $10,88 \mathrm{bc}$ & $14,45 \mathrm{~b}$ & 5,57 & 3,70 a & 4,09 & $3,90 \mathrm{ab}$ & 3,82 & $\mathrm{a}$ & 5,72 & $0,89 \mathrm{~b}$ \\
\hline $\mathrm{F}_{2}$ recíproco & 10,98 bc & $14,72 \mathrm{~b}$ & 5,62 & 3,70 a & 3,85 & $3,53 \mathrm{~b}$ & 3,73 & $a b$ & 5,78 & $0,92 \mathrm{~b}$ \\
\hline $\mathrm{RCP}_{1}$ & $10,76 \mathrm{bc}$ & $14,13 \mathrm{~b}$ & 5,48 & 3,50 a & 3,71 & $3,77 \mathrm{ab}$ & 3,78 & $\mathrm{a}$ & 5,80 & $0,90 \mathrm{~b}$ \\
\hline $\mathrm{RCP}_{2}$ & $11,02 \mathrm{bc}$ & $14,32 \mathrm{~b}$ & 5,67 & 3,62 a & 3,72 & $3,69 \mathrm{ab}$ & 3,66 & $\mathrm{ab}$ & 5,34 & $0,93 \mathrm{~b}$ \\
\hline Média & 11,42 & 14,93 & 5,59 & 3,47 & 3,77 & 3,46 & 3,47 & & 6,03 & 0,93 \\
\hline $\mathrm{CVe}^{2} \%$ & 13,12 & 6,75 & 6,74 & 7,27 & 6,61 & 9,24 & 7,43 & & 10,92 & 7,36 \\
\hline \multirow{2}{*}{$\begin{array}{l}\text { Genitor e } \\
\text { Geração }\end{array}$} & \multicolumn{10}{|c|}{ Aminoácidos essenciais } \\
\hline & Metionina & Lisina Fen & ilalanina & Leucina & Isoleucina & Histidina & Valina & Tre & eonina & $\begin{array}{c}\text { Proteína } \\
\text { Bruta }\end{array}$ \\
\hline BRS Valente & $0,79 \mathrm{~d}^{*}$ & $5,85^{\text {ns }}$ & 5,17 ns & 6,67 ns & $3,93^{\mathrm{ns}}$ & 2,14 ns & $4,46^{\mathrm{ns}}$ & & $44 \mathrm{~d}^{*}$ & $29,90 \mathrm{ab}^{*}$ \\
\hline IAPAR 44 & $0,97 \mathrm{abc}$ & 6,26 & 4,63 & 6,64 & 3,80 & 2,14 & 4,15 & &, $60 \mathrm{bc}$ & 31,80 a \\
\hline $\mathrm{F}_{1}$ & $0,97 \mathrm{abc}$ & 5,76 & 5,24 & 7,83 & 4,52 & 3,02 & 5,20 & &, $84 \mathrm{abc}$ & $26,59 \mathrm{bcd}$ \\
\hline $\mathrm{F}_{1}$ recíproco & $0,87 \mathrm{~cd}$ & 5,03 & 4,60 & 6,76 & 3,80 & 2,69 & 4,33 & & $47 \mathrm{c}$ & $28,68 \mathrm{abc}$ \\
\hline $\mathrm{F}_{2}$ & $1,09 \mathrm{a}$ & 5,68 & 5,12 & 7,43 & 4,15 & 2,69 & 4,91 & & 25 a & 21,40 e \\
\hline $\mathrm{F}_{2}$ recíproco & $1,02 \mathrm{abc}$ & 5,44 & 4,95 & 7,08 & 3,97 & 2,70 & 4,65 & & $=07 \mathrm{ab}$ & 22,71 de \\
\hline $\mathrm{RCP}_{1}$ & $1,04 \mathrm{ab}$ & 5,50 & 5,03 & 7,17 & 3,98 & 2,59 & 4,70 & & $399 \mathrm{abc}$ & 23,75 cde \\
\hline $\mathrm{RCP}_{2}$ & $0,91 \mathrm{bcd}$ & 5,58 & 4,69 & 7,00 & 3,52 & 2,86 & 4,05 & &, $06 \mathrm{ab}$ & 22,33 de \\
\hline Média & 0,98 & 5,62 & 4,95 & 7,11 & 3,98 & 2,62 & 4,60 & &, 80 & 25,13 \\
\hline $\mathrm{CVe} \%^{(1)}$ & 7,73 & 9,30 & 8,53 & 8,32 & 8,63 & 13,00 & 8,93 & & ,22 & 9,57 \\
\hline Adequado $^{(2)}$ & $1,7^{(3)}$ & 1,6 & $1,9^{(4)}$ & 1,9 & 1,3 & 1,6 & 1,3 & &, 99 & - \\
\hline
\end{tabular}

*Médias não seguidas de mesma letra, na vertical, diferem a 5\% de probabilidade pelo teste t. ns: não significativo. $\left({ }^{1}\right)$ CVe\%: Coeficiente de variação experimental. $\left({ }^{2}\right)$ Valores de aminoácidos considerados adequados pela FAO (1998) para suprir as necessidades diárias de um indivíduo adulto. $\left({ }^{3}\right)$ Metionina + cisteína. $\left({ }^{4}\right)$ Fenilalanina + tirosina. 
Gerações precoces com alto teor de metionina nos grãos foram obtidas a partir dos cruzamentos controlados realizados com um parental de alto teor de metionina (IAPAR 44: 0,97 gramas por $16 \mathrm{~g} \mathrm{~N}$ ) (Tabela 1). A utilização de parentais contrastantes para teor de metionina, também possibilitou a Kelly e Bliss (1975) a obtenção de plantas $F_{2}$ com alto teor de metionina e a observação de que a ação gênica aditiva predomina para esse caráter. Como a variância aditiva é de grande importância no melhoramento de plantas autógamas, pois não segrega de geração para geração, espera-se facilidade na seleção para o incremento do teor de metionina em feijão.

$\mathrm{O}$ teor de treonina foi superior na geração $\mathrm{F}_{2}$ $(4,25$ gramas por $16 \mathrm{~g} \mathrm{~N})$ e, nas demais gerações precoces, foi similar ao da cultivar IAPAR 44 (Tabela 1). Apenas na cultivar BRS Valente havia um teor inferior de treonina $(2,44 \mathrm{~g}$ por $16 \mathrm{~g} \mathrm{~N}$ da MS), mas este conteúdo não restringe a sua utilização na alimentação, de acordo com o padrão recomendado pela FAO (FAO, 1998).

O teor dos demais aminoácidos essenciais não foi alterado em gerações precoces, pois não foram observadas diferenças significativas. Assim, a partir do cruzamento entre BRS Valente e IAPAR 44 obtiveram-se gerações precoces de feijão com teores de aminoácidos essenciais semelhantes aos verificados em cultivares de feijão disponíveis para o cultivo no Brasil (ANTUNEs et al., 1995; Ribeiro et al., 2007). Além disso, os teores de lisina, fenilalanina, leucina, isoleucina, histidina, valina e treonina, nas diferentes gerações, foram superiores aos de padrão considerado adequado pela Organização das Nações Unidas para Agricultura e Alimentação (Tabela 1), para suprir as necessidades diárias de um indivíduo adulto (FAO, 1998).

Os menores valores de cisteína foram registrados nas gerações precoces (Tabela 1). Como a cisteína é o aminoácido não-essencial presente em menor concentração no feijão (ANTUNES et al., 1995; Ribeiro et al., 2007), é necessário averiguar se o somatório metionina + cisteína é superior a $1,7 \mathrm{~g}$ por $16 \mathrm{~g} \mathrm{~N}$ da MS, como recomendado pela FAO (1998). Desse modo, apenas nas gerações $F_{1}$ e $\mathrm{F}_{1}$ recíproco não havia valores de metionina + cisteína adequados para suprir as necessidades nutricionais diárias de um indivíduo adulto (FAO, 1998) e a complementação com outros alimentos é recomendada para que se obtenha melhor qualidade protéica. Para as gerações $F_{2}$ e $F_{2}$ recíproco não foi constatado deficiência em aminoácidos sulfurados (metionina + cisteína) e plantas $\mathrm{F}_{2}$ poderão ser selecionadas pelo programa de melhoramento para constituírem populações segregantes com alto teor desses aminoácidos.

Considerando os aminoácidos não essenciais com variabilidade, os parentais BRS Valente e IAPAR 44 não foram contrastantes para ácido aspártico, glicina, prolina, tirosina e cisteína (Tabela 1). No entanto, gerações precoces com baixo teor de ácido aspártico e de cisteína e com alto teor de prolina e de tirosina foram obtidas, indicando efeito de dominância e/ou sobredominância para esses caracteres, pois observou-se segregação transgressiva. Valores tão elevados de tirosina em germoplasma de feijão ainda não haviam sido registrados na literatura.

Com relação ao teor de ácido glutâmico, não se constataram diferenças significativas entre a cultivar IAPAR 44 e os valores observados nas gerações precoces. Além disso, a cultivar BRS Valente foi a que apresentou o maior valor para ácido glutâmico. Para os aminoácidos não-essenciais serina, alanina e arginina, não foram observadas diferenças significativas para os genótipos avaliados, caracterizando ausência de variabilidade genética.

As duas primeiras variáveis canônicas explicaram $99,28 \%$ da variação total dos genótipos, sendo $96,79 \%$ das diferenças entre os genitores e as gerações obtidas relativas à primeira variável canônica e 2,49\%, à segunda variável canônica. Com os escores das variáveis canônicas, três grupos foram formados (Tabela 2). O grupo 1 foi composto pela cultivar BRS Valente que se diferenciou dos demais devido aos elevados teores de ácido aspártico e de ácido glutâmico e aos baixos teores de glicina, prolina, tirosina, metionina e treonina.

O grupo 2 foi constituído pela cultivar IAPAR 44, que possui alto teor de metionina, cisteína, treonina e glicina. O cruzamento entre esses genitores resultou no desenvolvimento das gerações precoces (Grupo 3) com manutenção dos teores de metionina, treonina e glicina da cultivar IAPAR 44. Os teores de prolina e de tirosina foram superiores aos valores obtidos em qualquer um dos parentais avaliados e, os teores de ácido aspártico e de cisteína foram inferiores.

Os resultados dos experimentos revelaram que o cruzamento entre duas cultivares contrastantes quanto ao teor de metionina resulta em genótipos passíveis de seleção para elevado teor de metionina, sem comprometimento da disponibilidade dos demais aminoácidos. 
Tabela 2. Teores médios de aminoácidos (em gramas por $16 \mathrm{~g}$ de $\mathrm{N}$ da matéria seca) dos três grupos formados a partir do cruzamento entre BRS Valente e IAPAR 44, com base na matriz das distâncias de Mahalanobis, utilizando variáveis canônicas

\begin{tabular}{lcccccccc}
\hline Grupo $^{(1)}$ & Ácido aspártico & Ácido glutâmico & Glicina & Prolina & Tirosina & Cisteína & Metionina & Treonina \\
\hline 1 & $16,04 \mathrm{a}^{*}$ & $18,25 \mathrm{a}$ & $2,70 \mathrm{~b}$ & $1,80 \mathrm{~b}$ & $2,44 \mathrm{~b}$ & $1,20 \mathrm{a}$ & $0,79 \mathrm{~b}$ & $2,44 \mathrm{~b}$ \\
2 & $13,24 \mathrm{~b}$ & $15,10 \mathrm{~b}$ & $3,21 \mathrm{a}$ & $2,14 \mathrm{~b}$ & $2,87 \mathrm{~b}$ & $1,28 \mathrm{a}$ & $0,97 \mathrm{a}$ & $3,60 \mathrm{a}$ \\
3 & $10,61 \mathrm{c}$ & $14,50 \mathrm{~b}$ & $3,60 \mathrm{a}$ & $3,83 \mathrm{a}$ & $3,68 \mathrm{a}$ & $0,86 \mathrm{~b}$ & $0,99 \mathrm{a}$ & $4,00 \mathrm{a}$ \\
\hline Média geral & 11,42 & 14,93 & 3,47 & 3,46 & 3,47 & 0,93 & 0,97 & 3,80 \\
\hline
\end{tabular}

* Médias não seguidas de mesma letra, na vertical, diferem a 5\% de probabilidade pelo teste t. ${ }^{\text {ns: }}$ não significativo.

(1) Grupo: 1: BRS Valente; 2: IAPAR 44; 3: demais gerações.

\section{AGRADECIMENTOS}

Ao Conselho Nacional de Desenvolvimento Científico e Tecnológico (CNPq) e à Coordenação de Aperfeiçoamento de Pessoal de Nível Superior (CAPES) pelo auxílio financeiro e pelas bolsas concedidas.

\section{REFERÊNCIAS}

ABD EL-SAMEI, M.H.; LÁSZTITY, R. Comparative study on the amino acids composition in three local Phaseolus vulgaris seeds varieties. Zeitschrift für Lebensmitteluntersuchung und - Forschung A, v.178, p.24-26, 1984.

ANTUNES, P.L.; BILHALVA, A.B.; ELIAS, M.C.;SOARES, G.J.D. Valor nutricional de feijão (Phaseolus vulgaris, L.), cultivares Rico 23, Carioca, Piratã-1 e Rosinha-G2. Revista Brasileira de Agrociência, v.1, p.12-18, 1995.

AOAC INTERNACIONAL (Gaithersburg, Estados Unidos). Official methods of analysis of AOAC Internacional. $16^{\text {th }} \mathrm{ed}$. Washington: AOAC, 1995. 200p.

CRUZ, C.D.; REGAZZI, A.J. Modelos biométricos aplicados ao melhoramento genético. 2.ed. Viçosa: UFV, 2001. 390p.

ELKIM, R.G.; WASYNEZUK A.M. Amino acid analysis of feedstuff hydrolysates by precolum derivatization with phenylisothiocyanate and reversed-phase high performance liquid chromatography. Cereal Chemistry, v.64, p.226-229, 1987.

FAO. Junta de Conselho de Especialistas FAO/WHO/ONU. Necessidades de energia e proteína. São Paulo: Roca, 1998. 225 p.

FONSECA MARQUES, M.F.; BORA, P.S. Composición química y análisis de aminoácidos de alubias. Ciencia y Tecnología Alimentaria, v.2, p.248-252, 2000.

GUZMÁN-MALDONADO, S.H.; ACOSTA-GALLEGOS, J.; PAREDES-LÓPEZ, O. Protein and mineral content of a novel collection of wild and weedy common bean (Phaseolus vulgaris L). Journal of the Science of Food and Agriculture, v.80, p.1874$1881,2000$.
HAGEN, S.R.; FROST, B.; PRECOLUM, J. A. Phenylisothiocyanate derivatization and liquid chromatography of aminoacids in food. Journal Association of Analysis Chemistry, v.2, p.622-626, 1989.

HOSFIELD, G.L. Genetic control of production and food quality factors in dry bean. Food Technology, v.45, p.98-103, 1991.

KELLY, J.D.; BLISS, F.A. Heritability estimates of percentage seed protein and available methionine and correlations with yield in dry beans. Crop Science, v.15, p.753-757, 1975.

MORROW, B. The rebirth of legumes. Food Technology, v.45, p.96-121, 1991.

PIRES, C.V.; OLIVEIRA M.G.A.; ROSA, J.C.; COSTA, N.M.B. Qualidade nutricional e escore químico de aminoácidos de diferentes fontes protéicas. Ciência e Tecnologia dos Alimentos, v.26, p.179-187, 2006.

RIBEIRO, N.D.; LONDERO, P.M.G.; CARGNELUTTI FILHO, A.; JOST, E.; POERSCH, N.L.; MALLMANN, C.A. Composição de aminoácidos de cultivares de feijão e aplicações para o melhoramento genético. Pesquisa Agropecuária Brasileira, v.42, p.1393-1399, 2007. 